\title{
GOVERNANÇA CORPORATIVA E CUSTO DE CAPITAL DE TERCEIROS: EVIDÊNCIAS ENTRE EMPRESAS BRASILEIRAS DE CAPITAL ABERTO
}

\author{
Camila Veneo Campos Fonseca* \\ camilaveneo@yahoo.com.br \\ Rodrigo Lanna Franco da Silveira* \\ rlanna@unicamp.br \\ *Universidade Estadual de Campinas - Campinas, SP / Brasil
}

http://dx.doi.org/10.1590/1413-2311.016162016.62739

Recebido em 04/03/2016

Aprovado em 30/05/2016

Disponibilizado em 06/06/2016

Avaliado pelo sistema "double blind review"

Revista Eletrônica de Administração

Editora-chefe: Aurora Zen

ISSN 1413-2311 (versão "on line")

Editada pela Escola de Administração da Universidade Federal do Rio Grande do Sul.

Periodicidade: Quadrimestral

\section{RESUMO}

O reduzido acesso ao capital de terceiros, especialmente os de mais longo prazo, é um dos principais problemas do ambiente corporativo brasileiro. Conflitos de agência e existência de informação assimétrica nas transações efetivadas no mercado financeiro resultam no racionamento do crédito e no encarecimento do custo de capital. A adoção de melhores práticas de governança corporativa pelas empresas, ao implicar redução do custo de capital, amplia a captação de recursos para o investimento, mitigando o problema do financiamento empresarial. O objetivo deste estudo é avaliar a relação entre a adoção de melhores práticas de governança corporativa e o custo do capital de terceiros das empresas brasileiras não financeiras de capital aberto no período 2010-2014. De forma a atingir tal objetivo, foi utilizado um modelo de dados de painel com 230 companhias, sendo a estimação realizada pelo Método dos Momentos Generalizado Sistêmico (GMM-Sis). Os resultados apontaram que a adoção de melhores níveis de governança corporativa reduziu o custo do capital de terceiros das companhias presentes na amostra. Além disso, verificou-se que as variáveis custo de capital de terceiros do ano anterior, lucratividade e nível de emissão de ações preferenciais exerceram uma influência estatisticamente significativa sobre o custo contemporâneo da dívida.

Palavras-chave: governança corporativa; custo de capital; dados em painel; GMM sistêmico.

\section{CORPORATE GOVERNANCE AND COST OF DEBT: EVIDENCES AMONG BRAZILIAN LISTED COMPANIES}

\author{
ABSTRACT \\ REAd | Porto Alegre - Edição 83 - N 1 - Janeiro/Abril 2016 - p. 106-133
}




\section{GOVERNANÇA CORPORATIVA E CUSTO DE CAPITAL DE TERCEIROS:} EVIDÊNCIAS ENTRE EMPRESAS BRASILEIRAS DE CAPITAL ABERTO

The reduced access to debt capital, especially to long-term maturity debt, is one of the main problems of the Brazilian corporate environment. Agency conflicts and the existence of asymmetric information in transactions carried on the financial markets result in higher cost of capital and credit rationing. The adoption of best practices of corporate governance by enterprises, results in a reduced cost of capital, expands the role played by the market in raising funds for investment, and mitigates the problem of business financing. The purpose of this study is to evaluate the relationship between best practices of corporate governance and cost of debt among Brazilian non-financial listed companies during 2010-2014. Panel data with 230 companies and Generalized Method of Moments (GMM-Sis) method were used. Results suggested that a better corporate governance pattern has contributed to lowering the cost of debt of the companies. In addition, one-year-lagged cost of debt, profitability and issuance of preference shares have influenced the contemporary cost of debt.

Keywords: corporate governance; cost of capital; panel data; system GMM.

\section{GOBIERNO CORPORATIVO Y COSTE DE CAPITAL DE TERCEROS: EVIDENCIAS ENTRE EMPRESAS BRASILEÑAS DE CAPITAL ABIERTO RESUMEN}

La reducción del acceso al capital de terceros, especialmente a largo plazo, es uno de los principales problemas del entorno corporativo brasileño. Conflictos de agencia y la existencia de información asimétrica en las transacciones realizadas en los mercados financieros conducen al racionamiento del crédito y elevados costes de capital. La adopción de mejores prácticas de gobierno corporativo por las empresas y, por tanto, la reducción del costo de capital, amplía la captación de recursos de inversión, mitigando así el problema de las finanzas corporativas. El objetivo de este estudio es evaluar la relación entre la adopción de mejores prácticas de gobierno corporativo y el coste de la deuda de 230 empresas brasileñas no financieras de capital abierto en el periodo 2010-2014. Con el fin de lograr este objetivo, se utilizó un modelo de datos de panel con 230 empresas y el Método Generalizado de Momentos Sistémico (GMM-Sis). Los resultados mostraron que la adopción de mejores niveles de gobierno corporativo reduce el coste de la deuda de las compañías en la muestra. Además, se observó que el costo de la deuda pasada, la rentabilidad y el nivel de emisión de acciones preferentes tuvieron una influencia estadísticamente significativa sobre el costo de la deuda actual.

Palabras clave: gobierno corporativo; coste de capital; datos de panel; GMM sistémico.

\section{INTRODUÇÃO}

A governança corporativa consiste em um fator essencial à eficiente alocação de recursos e desenvolvimento do mercado de capitais (HEALY \& PALEPU, 2001). Por sua relevância no que tange à dinâmica de uma economia de mercado, tal temática vem se destacando nas pesquisas desenvolvidas no âmbito das finanças corporativas. Particularmente, seja devido à sua comprovada influência sobre o valor de longo prazo da empresa (KAPPLER; LOVE, 2002; FERREIRA et al., 2013; MELO et al., 2013; LAUTERBACH \& PAJUSTE, 2015), seja em resposta a uma maior preocupação quanto à otimização do 


\section{Camila Veneo Campos Fonseca \& Rodrigo Lanna Franco da Silveira}

processo decisório na alta gestão empresarial (BARROS \& SILVEIRA, 2008), o padrão de governança corporativa se coloca como de grande relevância e interesse para pesquisadores, corporações e policy makers.

As práticas de governança corporativa se alicerçam em dois mecanismos fundamentais: nível de disclosure e proteção aos direitos e interesses de investidores externos, sendo esta última fortemente vinculada à estrutura societária das companhias. Neste sentido, as práticas de governança são interpretadas como mecanismos por meio dos quais se assegura o efetivo monitoramento das atividades administrativas, assim como o estabelecimento dos incentivos apropriados para que investidores externos sejam resguardados da expropriação por gestores e acionistas controladores (BUSHMAN \& SMITH, 2001; LA PORTA et al., 2000).

Segundo Shleifer e Vishny (1997, p. 737), a governança corporativa "lida com as formas pelas quais os provedores de financiamento asseguram a obtenção de um retorno sobre os seus investimentos". Ou seja, o modo como uma corporação é gerida, seu nível de disclosure e estrutura proprietária influenciam diretamente a percepção dos provedores de capital, alterando a capacidade das empresas de acessarem o capital de terceiros, particularmente de longo prazo, assim como as condições creditícias, tanto em termos de montante, quanto, e principalmente, no que tange aos seus custos. Nesse contexto, o objetivo desta pesquisa é avaliar se a adoção de melhores práticas de governança impactou o custo do capital de terceiros das empresas brasileiras não financeiras de capital aberto entre 2010 e 2014. A hipótese a ser testada é a de que um melhor padrão de governança resulta na redução do custo do capital de terceiros.

Significativa parcela dos trabalhos voltados à análise da relação entre adoção de melhores práticas de governança e alternativas de financiamento no Brasil mensura a influência da primeira sobre o nível de endividamento e o custo do capital próprio (CICOGNA et al., 2007; SOARES \& KLOECKNER, 2008; SILVEIRA et al., 2008b; MIGLANI et al., 2015). Poucos estudos concentram a análise na relação entre governança e custo de capital de terceiros, sendo a maioria deles restrita a um dos mecanismos de governança, especificamente o nível de disclosure (LIMA, 2009; ANGONESE et al., 2013). Neste sentido, o presente trabalho contribui para a literatura tanto por dedicar-se à análise da relação entre a governança e o custo do capital de terceiros, quanto por empregar um modelo dinâmico, estimado pelo Método dos Momentos Generalizado Sistêmico (GMM-Sis), capaz de lidar com os problemas de endogeneidade comuns em pesquisas na área (BLUNDELL \& BOND, 1998).

REAd | Porto Alegre - Edição 83 - N 1 - Janeiro/Abril 2016 - p. 106-133 
GOVERNANÇA CORPORATIVA E CUSTO DE CAPITAL DE TERCEIROS:

EVIDÊNCIAS ENTRE EMPRESAS BRASILEIRAS DE CAPITAL ABERTO

O estudo está organizado em três tópicos além desta introdução e das considerações finais. O primeiro consiste em uma revisão da literatura com ênfase na relação entre os principais mecanismos internos de governança e o custo do capital de terceiros. No segundo, a metodologia adotada é apresentada e, na sequência, os resultados são avaliados.

\section{REVISÃO DE LITERATURA}

\subsection{Relação entre disclosure e custo do capital de terceiros}

Os conceitos de disclosure, divulgação, evidenciação e transparência são, em geral, tratados como sinônimos na literatura. Nesta pesquisa, assume-se que tais conceitos tratam da divulgação ampla e aprofundada das informações econômicas e financeiras, boas e ruins, relevantes e críveis de uma determinada empresa e seus projetos.

O nível de evidenciação, por responder à iniciativa das empresas de assegurar a capacidade de monitoramento e viabilizar a formação das expectativas dos investidores resguardando-os dos custos da assimetria informacional e do conflito de agência, é um dos principais mecanismos internos de governança corporativa (HEALY \& PALEPU, 2001). As informações veiculadas podem exceder o requerido por lei, traduzindo-se na forma do disclosure voluntário de informações adicionais ou da autoindução ao disclosure resultante da dinâmica entre a empresa e os investidores (WATSON et al., 2002; RONEN \& YAARI, 2002).

O efeito do nível de evidenciação sobre a percepção dos investidores tem como principal causa a assimetria informacional entre os últimos e aqueles que administram os recursos corporativos. Por não possuírem informações equânimes sobre a natureza da transação, os investidores ficam sujeitos a dois problemas principais: seleção adversa e risco moral. A seleção adversa diz respeito à incapacidade do investidor de identificar as melhores oportunidades de investimento, de tal forma que o custo do capital passa a ser calculado a partir do risco médio associado a todos os projetos. Já o risco moral advém da possibilidade do tomador agir de forma oportunista depois de firmado o contrato entre as partes, também impactando negativamente o custo dos recursos (MYERS, 1984; STIGLITZ, 1991). A divulgação das informações relevantes acerca dos resultados operacionais e oportunidades de investimento da empresa torna-se um mecanismo eficaz para balizar a tomada de decisão dos investidores, influenciando positivamente suas expectativas e ampliando a demanda por títulos (HAIL, 2002).

Motivada pelo reconhecimento da importância da divulgação para diferenciar empresas no que tange as suas vantagens competitivas e, por consequência, para a eficiente 


\section{Camila Veneo Campos Fonseca \& Rodrigo Lanna Franco da Silveira}

alocação dos recursos, desenvolveu-se uma linha de pesquisa dedicada exclusivamente à compreensão do fenômeno da evidenciação, a chamada Teoria da Divulgação. Verrechia (2001) contribuiu para a construção de um framework das pesquisas na área ao desenvolver uma tipologia que as classifica em três categorias: divulgação baseada na associação, na discricionariedade e na eficiência. A tipologia diferencia os trabalhos pelo foco, respectivamente, na mudança do comportamento dos investidores frente à divulgação, no trade-off dos gerentes entre divulgar ou omitir informações internas e na decisão do que divulgar na ausência de conhecimento prévio quanto ao impacto da divulgação no mercado. Para o autor, a busca pela redução da assimetria informacional é a base para o desenvolvimento de uma teoria abrangente uma vez que figura como pré-requisito para a integração entre os incentivos para divulgar, a eficiência da divulgação e a interação endógena entre insiders e outsiders via mercado de capitais.

Nesse contexto, o debate sobre a necessidade de haver um equilíbrio entre os custos e benefícios da divulgação é relativizado. Isto porque, mesmo que o mercado interpretasse a não-divulgação como uma perspectiva desfavorável quanto ao desempenho da empresa, na ausência de um maior detalhamento das suas condições, o investidor seria incapaz de mensurar o nível de dificuldade em que a companhia se encontra. A depender do seu grau de desconfiança, o investidor poderia assumir uma postura de aversão ao risco, optando pelo racionamento do crédito. Em contrapartida, a redução da assimetria, propiciada pela divulgação das informações, ao influenciar as expectativas dos investidores, tornar-se-ia imprescindível à captação de recursos a menores custos, sobrepondo os benefícios aos custos.

Em síntese, empresas comprometidas com o detalhamento das informações divulgadas tendem a ter menor custo do capital, dado que ampliam o acesso dos agentes externos às informações da empresa, fornecendo a estes uma maior capacidade de avaliar os riscos envolvidos no investimento, monitorar e disciplinar a alocação de recursos pelos gestores e mitigar as chances de expropriação (BUSHMAN \& SMITH, 2001; EASLEY \& O’HARA, 2004). A divulgação ampla e profunda das condições econômico-financeiras da empresa e do projeto a ser financiado permitiria que investidores externos alocassem de modo mais eficiente seus recursos, ampliando a demanda pelos títulos e a sua liquidez, reduzindo o custo do capital (LANZANA et al., 2006; LIMA, 2009; ANGONESE et al., 2013).

A maior parte das pesquisas empíricas baseadas na Teoria da Divulgação concentra-se na análise dos determinantes do disclosure ou da influência deste último sobre o desempenho e o custo do capital próprio (HAIL, 2002; NAKAMURA et al., 2006; LANZANA et al., 2006; CUNHA \& RIBEIRO, 2008; CHENG et al., 2013). Um número limitado de estudos 
GOVERNANÇA CORPORATIVA E CUSTO DE CAPITAL DE TERCEIROS:

EVIDÊNCIAS ENTRE EMPRESAS BRASILEIRAS DE CAPITAL ABERTO

dedicou-se à verificação empírica do efeito da maior divulgação das informações sobre o custo do capital de terceiros, sendo a maioria deles específicos à análise da divulgação de informações voluntárias. Sengrupta (1998), por exemplo, abordou a relação entre a qualidade do disclosure e o prêmio de risco. A partir de uma amostra de 311 empresas norte-americanas para o período 1987-1991, verificou que um maior disclosure levou à menor custo da dívida. Além disso, os resultados indicaram que este fator foi ainda mais importante para empresas associadas a uma elevada incerteza de mercado. Zhu (2014) verificou que empresas com boa governança defrontaram-se com menores custos de capital próprio e de terceiros no período 2006-2009. Enquanto a relação entre governança corporativa e custo do capital próprio foi mais pronunciada em países com um sistema jurídico eficiente, práticas de divulgação abrangentes e governos de maior qualidade, a relação entre a primeira e o custo do capital de terceiros foi maior em países caracterizados por uma fraca proteção legal aos direitos de investidores externos, reduzida transparência e governos de pior qualidade.

Para o mercado brasileiro, Lima (2009), a partir de uma amostra de 23 companhias abertas, encontrou indícios de uma relação negativa entre nível de disclosure voluntário e custo dívida no período 2000-2004. Castro e Martinez (2009) também partiram da hipótese da existência de uma relação negativa entre nível de evidenciação de informações voluntárias na internet e custo da dívida. Os resultados da pesquisa, aplicada a 133 empresas entre 2003 e 2007, indicaram que as variáveis foram negativamente correlacionadas, apesar de, na análise de regressão linear, a variável 'evidenciação' não ser estatisticamente significante. Por fim, Angonese et al. (2013) verificaram se o nível de evidenciação de informações voluntárias figurou como um dos determinantes do custo do capital de terceiros das 100 empresas mais negociadas na BM\&FBOVESPA no último trimestre de 2009. Os resultados forneceram indícios de que o nível de evidenciação foi negativamente correlacionado com o custo do capital de terceiros, apesar da variável de interesse, também nesse caso, não ter sido estatisticamente significante.

\subsection{Relação entre estrutura de propriedade e custo do capital de terceiros}

Em grande medida devido à necessidade de captar recursos para financiamento do investimento, o processo de constituição das grandes corporações contemporâneas esteve estreitamente associado à dispersão da estrutura acionária. A separação entre propriedade e controle, ao exigir a transferência da autoridade quanto à tomada de decisão dos acionistas 


\section{Camila Veneo Campos Fonseca \& Rodrigo Lanna Franco da Silveira}

para os executivos, criou custos associados ao conflito de interesses ${ }^{1}$, sendo este o principal problema da governança corporativa nos países onde tal fenômeno foi observado (BERLE \& MEANS, 1932; JENSEN \& MECKLING, 1976).

A estrutura de propriedade pulverizada, no entanto, é uma realidade majoritariamente restrita ao contexto anglo-saxão. Na grande maioria dos países, inclusive no Brasil, a estrutura societária é altamente concentrada, observando-se uma sobreposição entre controle e gestão nas companhias. Nestes países, o principal problema da governança advém não do conflito de agência entre acionistas e gestores, mas, sim, da expropriação de minoritários e credores por acionistas controladores (LA PORTA et al., 2000; BUSHMAN \& SMITH, 2001).

Se, por um lado, um alto grau de concentração da propriedade pode resultar num maior interesse de acionistas controladores em coletar informações e monitorar a atividade gerencial, pressionando os gestores por melhores resultados, por outro, a presença de grandes acionistas e a eventual busca por benefícios privados de controle, à custa da expropriação dos demais investidores, podem comprometer desde a gestão até processos de reestruturação, resultando em perdas de desempenho e geração de valor. A percepção dos investidores de que o domínio do processo decisório por controladores pode ser lesivo aos seus interesses e aos da própria companhia - risco de expropriação e econômico - resultaria, portanto, em uma menor liquidez do mercado acionário e na cobrança de maiores taxas pela utilização do capital de terceiros (MAYER, 1996; SHLEIFER \& VISHNY, 1997; BEBCHUK, 1999; CLAESSENS et al., 2002).

Segundo Shleifer e Vishny (1997), para que se efetivem os ganhos em termos de maximização do valor da companhia e mitigação da assimetria de informação e interesses entre os agentes envolvidos na companhia, o acionista controlador deve reconhecer nesta maximização um benefício superior àquele alcançado ao agir em benefício próprio. Neste contexto, a existência de grandes acionistas controladores leva a dois tipos de efeitos sobre a empresa, denominados de efeito-incentivo e entrincheiramento. $\mathrm{O}$ primeiro tem base no fato de, ao possuir o controle da empresa e ter uma significativa participação sobre o capital total (direito ao fluxo de caixa), o acionista possui incentivo para coletar informações e monitorar os gestores no sentido de maximizar a riqueza da corporação. Por outro lado, o efeitoentrincheiramento se observa quando, a partir de certo nível de concentração da propriedade,

\footnotetext{
${ }^{1}$ A explicação para a desavença de interesses entre agente e principal, formalizada pela Teoria da Agência como conflito de agência, e reside no fato de que nenhum indivíduo desejará maximizar uma função de utilidade que não a sua própria. Os gestores tenderão sempre a buscar atender aos seus próprios interesses em detrimento dos interesses dos acionistas. Os custos de agência, pressuposta a inexistência de contratos completos, são os incorridos devido tanto à tentativa de alinhar estes interesses, quanto às perdas em termos de eficiência pelo conflito não ser solucionado (JENSEN \& MECKLING, 1976).
}

REAd | Porto Alegre - Edição 83 - N 1 - Janeiro/Abril 2016 - p. 106-133 
GOVERNANÇA CORPORATIVA E CUSTO DE CAPITAL DE TERCEIROS:

EVIDÊNCIAS ENTRE EMPRESAS BRASILEIRAS DE CAPITAL ABERTO

os grandes acionistas passam a buscar benefícios próprios à custa dos demais investidores como, por exemplo, manter-se indefinidamente no cargo de direção com altos salários (SILVEIRA et al., 2004). Tal efeito negativo está diretamente associado ao direito ao controle da empresa (direito de voto). Dessa forma, o impacto lesivo do conflito de agência entre insiders e outsiders sobre o custo do capital é progressivamente maior com a elevação do afastamento entre o direito de controle e o direito sobre o fluxo de caixa. Em outras palavras, ao inexistirem mecanismos de controle ou verificarem-se artifícios capazes de garantir a manutenção do controle sem o devido efeito-incentivo, maior seria o custo do capital da companhia (HARRIS \& RAVIV, 1988; STULZ, 1988; CLAESSENS et al.,2002).

No Brasil, uma das principais causas da disparidade entre o direito de controle e a participação no capital total da empresa esteve na permissividade quanto à emissão de ações preferenciais (PN), o que levou ao afastamento da relação uma ação - um voto no país. Desde 1976 (lei n⿳o 6.404) até 2001 (lei n⿳o 10.303), o percentual máximo de participação das ações PN era de 2/3 (dois terços) do total de ações emitidas. No caso limite em que somente 1/3 das ações fossem ordinárias $(\mathrm{ON})$, a propriedade de 16,66\% do capital social da companhia seria condição mínima necessária para que se exercesse seu controle. Ou seja, a alteração na proporcionalidade entre as classes de ação emitidas propiciou o desalinhamento entre o montante investido e o poder de controle e, portanto, o questionamento em relação não só à participação relativa dos que controlam as decisões corporativas, mas também dos incentivos à expropriação dos minoritários (CARVALHO, 2002; LEAL et al., 2002; SILVEIRA et al., 2004).

Não obstante, o cenário de elevada emissão de ações PN e concentração das ações ON tornou os mecanismos de mercado inócuos na amenização do problema da reduzida proteção aos acionistas minoritários. Claessen et al. (2000) atribuíram tal fato à liquidez associada às ações PN. A emissão desproporcional de ações PN, acompanhada do fato das ações ON serem usualmente negociadas em grandes blocos fora do mercado, resultou no descolamento entre o valor intrínseco das primeiras - reduzido devido ao risco de expropriação - e o valor pelo qual elas são transacionadas. Atribui-se, portanto, um prêmio de liquidez superior às ações $\mathrm{PN}$, o que, além de encobrir o benefício marginal das ações $\mathrm{ON}$, torna o próprio funcionamento do mercado um incentivo para que acionistas majoritários expropriem os demais.

A Lei $n^{\circ} 10.303 / 2001$ suspendeu a cláusula que viabilizava a manutenção do controle com menos de $17 \%$ do capital, reintroduzindo um limite superior de $50 \%$ do total das ações para a emissão de ações PN. No entanto, apesar do esforço institucional de amenizar os 


\section{Camila Veneo Campos Fonseca \& Rodrigo Lanna Franco da Silveira}

efeitos lesivos da separação entre o direito de controle e o direito sobre o fluxo de caixa, esta diferença segue sendo expressiva nas empresas brasileiras de capital aberto, principalmente entre aquelas não comprometidas com um elevado padrão de governança (LEAL et al., 2002; SILVEIRA et al., 2008a; CAIXE \& KRAUTER, 2013). Tal cenário corrobora a importância de se discutir o efeito da adoção de melhores práticas na redução da capacidade de expropriação de acionistas controladores e, consequentemente, melhora da percepção de risco dos investidores externos e redução do custo do capital.

Uma série de trabalhos dedicou-se à avaliação dos efeitos da concentração da propriedade e do controle, ou da diferença entre ambas, sobre variáveis como o valor de mercado da companhia e os ratings de crédito das debêntures. Claessens et al. (2002), a partir de uma amostra de 1.301 empresas leste-asiáticas em 1996, encontraram uma relação positiva entre aumento da participação do maior acionista no fluxo de caixa e o valor da empresa, explicada pelo efeito-incentivo. Por outro lado, o aumento do poder de controle do maior acionista, principalmente quando não houve correspondência na participação no fluxo de caixa, associada pelos autores ao efeito-entrincheiramento, resultou numa perda de valor para a empresa. Adicionalmente, Khurana et al. (2013) investigaram a influência que o afastamento entre direito ao fluxo de caixa e direito de voto teve sobre a divulgação de relatórios financeiros com informações negativas a respeito da companhia. Os resultados apontaram que a concentração do direito de controle impactou negativamente a transparência, estando associada a uma menor agilidade em reconhecer más notícias via relatórios financeiros. Já Lauterbach e Pajuste (2015) verificaram 121 unificações voluntárias de duas classes de ações, na Europa, no período 1996-2009. Os resultados apontaram que a melhora do padrão de governança, com o fim da disparidade entre direito de voto e direito de propriedade e, associadamente, à redução do poder de controle dos acionistas controladores, teve um efeito positivo sobre o valor da companhia.

Com foco no mercado brasileiro, Caixe e Krauter (2013), partindo de uma amostra de 237 empresas nacionais entre 2001 e 2010, verificaram que a concentração da propriedade e controle exerceu uma influência positiva sobre o valor de mercado das ações. No entanto, a relação entre as variáveis foi quadrática, ou seja, a partir de um nível ótimo de concentração, o aumento da participação do acionista controlador no fluxo de caixa da companhia teve um efeito negativo sobre o seu valor de mercado. Além disso, a concentração do direito de controle exerceu um impacto adverso sobre o valor de mercado corporativo. Tais conclusões corroboram a percepção da existência de um trade-off entre efeito-incentivo e efeitoentrincheiramento associado ao nível de concentração da propriedade.

REAd | Porto Alegre - Edição 83 - N 1 - Janeiro/Abril 2016 - p. 106-133 


\section{GOVERNANÇA CORPORATIVA E CUSTO DE CAPITAL DE TERCEIROS: EVIDÊNCIAS ENTRE EMPRESAS BRASILEIRAS DE CAPITAL ABERTO}

Campos (2006) analisou o efeito da concentração da propriedade sobre o desempenho corporativo. Companhias com propriedade concentrada apresentaram margens líquidas maiores que empresas com estrutura dispersa. No entanto, nos casos em que as famílias figuraram como majoritários, a margem líquida foi menor. Silva et al. (2012) investigaram a relação entre a governança corporativa e o rating das debêntures emitidas por 101 empresas brasileiras entre 2005 e 2010. Observou-se que empresas em que o maior acionista possuía um elevado percentual de ações com direito a voto tiveram melhores classificações de crédito.

\section{METODOLOGIA}

\subsection{Definição das variáveis do modelo}

Para verificar o impacto da adoção de melhores práticas de governança corporativa, assim como de outros atributos financeiros, no custo de capital das empresas, foi realizada, além da análise descritiva, uma modelagem econométrica com dados em painel - equação (1).

$$
\begin{aligned}
& K d_{i t}=\alpha+\beta_{1} K d_{i t-1}+\beta_{2} T_{A M}+\beta_{3} L U C R_{i t}+\beta_{4} V O L A T_{i t}+\beta_{5} D I V_{i t} \\
& +\beta_{6} P A R T_{i t}+\beta_{7} D I F_{i t}+\beta_{8} P N_{i t}+\beta_{9} N 2 N M_{i t}+\beta_{10} \sum_{i=1}^{T-1} A N O_{t}+a_{i}+\mu_{i t}
\end{aligned}
$$

Onde, $K d_{i t}$ é o custo de capital de terceiros para a empresa $i$ no ano $t ; T A M_{i t}$ e $L U C R_{i t}$ se referem, respectivamente, ao tamanho e à lucratividade da companhia $i$ no ano $t ; V O L A T_{i t} \mathrm{e}$ $D I V_{i t}$ consistem na volatilidade dos resultados da companhia ${ }^{2}$ e no nível de endividamento, respectivamente; $A N O_{t}$ se trata de uma variável binária que assume valor igual a um no $t$ ésimo ano e zero nos demais - esta variável capta os chamados 'efeitos fixos do tempo' geradores de correlação seccional ${ }^{3}$. Cabe ainda mencionar que o intercepto é representado por $\alpha$. O termo de erro do modelo é decomposto entre $a_{i}$, a heterogeneidade individual não observada e fixa no tempo das empresas da amostra, e um elemento não sistemático, $\mu_{i t}$, combinado da série temporal e do corte transversal.

A variável dependente do modelo, custo de capital $\left(K d_{i t}\right)$, é obtida pela razão entre as despesas financeiras líquidas do benefício fiscal $\left(D F_{t}\right)$ e o passivo oneroso - equação $(2)^{4}$.

\footnotetext{
${ }^{2}$ O cálculo da volatilidade dos resultados levou em conta o desvio padrão da razão entre EBITDA e Ativo Total considerando um período de três anos. Tal indicador teve base nos trabalhos de Bastos e Nakamura (2009), Silveira et al. (2008b), Perobelli e Famá (2003).

${ }^{3}$ No caso desta pesquisa, os efeitos fixos estão associados aos ciclos de negócios e de crédito, choques macroeconômicos ou qualquer outra variação anual da conjuntura econômica capaz de afetar as expectativas dos credores, alterando o custo do capital de terceiros.

${ }^{4}$ As despesas financeiras relativas aos empréstimos e financiamentos podem estar associadas a fatores que vão além das taxas de juros praticadas, tais como variações das taxas de câmbio nos casos em que a dívida é denominada em moeda estrangeira, existência de garantias para contratação do capital, possibilidade de conversão da dívida em ações, prazos de carência e etc. Neste sentido, uma empresa pode ter suas despesas financeiras alteradas independentemente do padrão de governança vigente. Apesar de o indicador utilizado apresentar tais limitações, julga-se relevante realizar o teste empírico proposto tendo em vista apresentar maiores indícios da relação entre governança corporativa e custo de capital de terceiros,
} 


\section{Camila Veneo Campos Fonseca \& Rodrigo Lanna Franco da Silveira}

$$
K d_{t}=\frac{D F_{t}}{F i n C P_{t-1}+F i n L P_{t-1}+D e b C P_{t-1}+D e b L P_{t-1}}
$$

Onde, FinCP $P_{t-1}$ e $F i n L P_{t-1}$ consistem, respectivamente, no financiamento de curto prazo e longo-prazo em $t-1$; $D e b C P_{t-1}$ e $D e b L P_{t-1}$ correspondem, respectivamente, ao valor das debêntures de curto prazo e longo prazo em $t-1$.

O Quadro 1 apresenta as variáveis de controle consideradas no estudo (relativas às características específicas das companhias) e a relação esperada entre tais indicadores e o custo da dívida.

Quadro 1 - Resumo das variáveis explicativas

\begin{tabular}{|lccc|}
\hline \multicolumn{1}{|c}{ Variável } & Sigla & Fórmula & $\begin{array}{r}\text { Relação } \\
\text { esperada }\end{array}$ \\
\hline \hline Tamanho & $T A M$ & $\ln (\mathrm{PL})$ & Negativa \\
Lucratividade & LUCR & $\frac{\text { EBITDA }}{\text { Vendas }}$ & Negativa \\
Volatilidade & VOLAT & DesvPad $\left(\frac{\text { EBITDA }}{\mathrm{AT}}\right)$ & Positiva \\
Nível de Endividamento & DIV & $\frac{\text { PC }+ \text { ELP }}{\text { PL }}$ & Positiva \\
\hline
\end{tabular}

Em que: PL = Patrimônio Líquido; EBITDA = Lucro Antes de Juros, Impostos, Depreciação e Amortização; AT = Ativo Total; $\mathrm{PC}=$ Passivo Circulante; ELP = Exigível de Longo Prazo.

Fonte: Elaboração própria.

Empresas maiores, por deterem maior capital e, portanto, possuírem maiores chances de internalizar funções originalmente atribuídas ao sistema financeiro, são mais capazes de contornar as ineficiências informacionais do mercado creditício. Além disso, por apresentarem maior diversificação dos seus negócios, têm reduzido seu risco de insolvência e falência (SILVEIRA et al., 2008b). Adicionalmente, empresas maiores costumam ter melhor reputação, característica que influi positivamente sobre a percepção dos agentes quanto ao risco do investimento. Por tais razões, grandes empresas tendem a acessar recursos externos a menores custos (CASTRO \& MARTINEZ, 2009).

Companhias com maior margem operacional e/ou resultados menos voláteis têm uma probabilidade menor de emitir títulos arriscados e/ou suspender investimentos promissores, o que, ao mitigar os custos de inadimplência e falência, faz com que elas se defrontem com

principalmente em virtude da escassez de estudos sobre o tema no Brasil. Vale ainda apontar que, de forma a minimizar os problemas apontados, como será mencionado mais adiante, foram estabelecidos critérios de exclusão de empresas que apresentaram custo de capital de terceiros excessivo, além de se incluírem dummies de ano, as quais objetivam captar efeitos do ambiente econômico. 
GOVERNANÇA CORPORATIVA E CUSTO DE CAPITAL DE TERCEIROS:

EVIDÊNCIAS ENTRE EMPRESAS BRASILEIRAS DE CAPITAL ABERTO

menores custos de endividamento. Dessa forma, quanto menor a lucratividade e maior a volatilidade, maiores os riscos percebidos pelos investidores, e, portanto, mais elevados os custos da dívida. Em relação ao nível de endividamento, empresas mais endividadas comprometem, ceteris paribus, parcela maior dos seus resultados com o pagamento de juros e amortizações, o que, ao aumentar os riscos de inadimplência e falência, encarece a taxa de juros dos empréstimos.

Em relação às variáveis explicativas de interesse, foram incluídos quatro indicadores, três referentes à estrutura de propriedade e um relativo à listagem em níveis diferenciados de governança corporativa - Quadro 2. Segundo Claessens et al. (2002), o efeito incentivo à coleta de informação e monitoramento da gestão está associado à participação no fluxo de caixa. Para captá-lo, definiu-se a variável PART como o percentual de participação do maior acionista no total de ações da companhia. O aumento da participação do maior acionista no capital total, por assegurar que seus retornos serão atingidos por suas decisões, por um lado, reduziria os incentivos à extração de benefícios privados de controle e, por outro, ampliaria o interesse na maximização do valor e na mitigação da assimetria de informação e de interesses entre insiders e outsiders. Assim, espera-se que quanto maior a participação do maior acionista no fluxo de caixa da companhia, menores os custos da dívida.

Em relação ao efeito-entrincheiramento, este é associado ao afastamento entre o poder para tomada de decisões e a participação no fluxo de caixa da companhia. Para captar essa diferença, utilizou-se a variável DIF definida como a diferença entre o percentual de participação do maior acionista no total de ações ordinárias e o percentual da sua participação no total de ações da companhia. Espera-se que quanto maior a diferença entre o direito de controle e o direito sobre o fluxo de caixa, maior o incentivo para a extração de benefícios privados e, portanto, maior o custo do capital de terceiros.

A partir da disseminação dos benefícios da adoção de melhores práticas de governança, muitas empresas reconheceram na proteção aos direitos dos investidores uma forma de reduzir seu custo de capital. Neste sentido, a adesão voluntária às práticas de somente emitir ações ordinárias e/ou conceder direitos adicionais aos preferencialistas, sinalizaria ao mercado um compromisso do controlador com a maximização do valor da companhia e a minimização da assimetria de informações, alterando as expectativas em prol da redução do custo do capital. Com o propósito de verificar tal fato, foi incluída no modelo a variável $P N$, definida como o percentual de ações PN emitidas pela companhia. 
Camila Veneo Campos Fonseca \& Rodrigo Lanna Franco da Silveira

Quadro 2 - Resumo das variáveis de interesse

\begin{tabular}{|c|c|c|c|}
\hline Variável & Sigla & Fórmula & $\begin{array}{l}\text { Relação } \\
\text { esperada }\end{array}$ \\
\hline Efeito-incentivo & $P A R T$ & $\frac{\text { № de ações do maior acionista }}{\text { Total de ações }(\mathrm{ON}+\mathrm{PN})}$ & Negativa \\
\hline Efeito-entrincheiramento & $D I F$ & $\frac{\text { № de ações ON do maior acionista }}{\text { Total de ações ON }}-P A R T$ & Positiva \\
\hline $\begin{array}{l}\text { Percentual de ações } \\
\text { preferenciais emitidas }\end{array}$ & $P N$ & $\frac{\mathrm{N}^{\mathrm{o}} \text { de ações PN }}{\text { Total de ações }(\mathrm{ON}+\mathrm{PN})}$ & Positiva \\
\hline Governança corporativa & $N 2 N M$ & $\begin{array}{l}N 2 N M=1 \text { se listada no } \mathrm{N} 2 \text { ou } \mathrm{NM} \\
N 2 N M=0 \text { caso contrário }\end{array}$ & Negativa \\
\hline
\end{tabular}

Em que: $\mathrm{ON}$ = ações ordinárias; $\mathrm{PN}$ = ações preferenciais; $\mathrm{N} 2$ = Nível 2; $\mathrm{NM}$ = Novo Mercado.

Fonte: Elaboração própria.

Em 2000, a BM\&FBOVESPA instituiu os segmentos especiais de listagem - Nível 1 (N1), Nível 2 (N2) e Novo Mercado (NM) - a fim de mitigar parte dos problemas da governança corporativa no Brasil por meio da criação de um "mercado paralelo" que promovesse e reconhecesse as boas práticas. A listagem nesses segmentos distingue as empresas em quesitos de governança tendo em vista seu comprometimento voluntário com a transparência das informações prestadas e a proteção aos investidores minoritários, sinal recebido positivamente pelo mercado e cuja repercussão se faz sentir tanto na cotação das ações, como no custo do capital de terceiros.

O diferencial do N1 se baseia na adoção de práticas que favoreçam a transparência e o acesso às informações pelos investidores. Especificamente, é exigido um detalhamento das informações divulgadas, ultrapassando as exigências previstas em lei, além de um free float mínimo de $25 \%$ do capital. No N2, apesar de prevista a elaboração das demonstrações financeiras de acordo com padrões internacionais, os principais avanços se dão na esfera da proteção aos acionistas minoritários, que passam a beneficiar-se de direitos adicionais. Por exemplo, é requerido o direito a um tag along de $100 \%$ no caso de venda do controle da empresa $^{5}$, e de voto em casos como a aprovação de fusões e incorporações e contratos entre a empresa e outras companhias do mesmo grupo controlador. No NM, além da adoção das regras previstas nos $\mathrm{N} 1$ e N2, as empresas emitem somente ações ordinárias ${ }^{6}$.

\footnotetext{
${ }^{5} \mathrm{O}$ tag along assegura aos detentores de ações PN o recebimento de parcela da quantia oferecida aos acionistas controladores nos casos em que haja fechamento de capital ou alienação do bloco de controle da companhia.

${ }^{6}$ Outro aspecto importante, obrigatório para companhias listadas no N2 e NM e facultativo para as demais, é a adesão à Câmara de Arbitragem, foro criado pela BM\&FBOVESPA para dinamizar a resolução de conflitos societários e do mercado de capitais.
}

REAd | Porto Alegre - Edição 83 - N 1 - Janeiro/Abril 2016 - p. 106-133 
GOVERNANÇA CORPORATIVA E CUSTO DE CAPITAL DE TERCEIROS:

EVIDÊNCIAS ENTRE EMPRESAS BRASILEIRAS DE CAPITAL ABERTO

Pressupõe-se, assim, que empresas certificadas por seu padrão de governança tenham melhores práticas relativas tanto à estrutura de propriedade e controle, quanto ao nível de evidenciação das informações. Nesse sentido, considerou-se uma variável dummy, $N 2 N M$, que assumiu valor igual a um a partir do ano em que a empresa ingressou no N2 ou NM. O resultado esperado é que as empresas listadas em tais níveis de governança, por concordarem voluntariamente com o cumprimento de critérios mais rígidos de divulgação das informações contábeis e financeiras e proteção aos investidores, diferenciam-se das demais, reduzindo o custo de captação de recursos.

É válido salientar que uma vantagem da utilização desta proxy é a análise de uma amostra maior de empresas, tendo em vista a dificuldade operacional no desenvolvimento de um índice de transparência para um número expressivo de companhias. A justificativa para a análise diferenciada entre o N1 e os outros dois segmentos, por sua vez, reside na percepção de que a adesão ao N2 e NM exerce um maior impacto sobre o custo do capital de terceiros, dada a maior rigidez das regras exigidas para a adesão a estes segmentos. Optou-se por não diferenciar empresas listadas no N2 daquelas listadas no NM uma vez que a única diferença entre elas reside na emissão de ações preferenciais no N2, efeito já captado pela variável PN.

\subsection{Método de estimação}

Para a estimação do modelo aplicou-se o GMM-Sis (BLUNDELL; BOND, 1998). Sua principal vantagem é possuir premissas menos restritivas que as exigidas pelos métodos tradicionais para estimação de modelos com dados em painel. Uma importante limitação do método dos mínimos quadrados ordinário (MQO) é não incorporar a heterogeneidade individual - ou seja, o modelo não abarca todas as características não observadas da amostra que possam afetar o custo do capital. Os métodos de Efeitos fixos e aleatórios (respectivamente, EF-Within e EA-MQG) podem capturar, ao menos parcialmente, a autocorrelação nos resíduos, assim como mitigar problemas de endogeneidade decorrentes de variáveis omitidas constantes no tempo. No entanto, os três métodos pressupõem a exogeneidade estrita das variáveis explanatórias em relação aos efeitos não observados. Este pressuposto prevê que não só o valor esperado da variável dependente, controlado pelos regressores e pela heterogeneidade não observada, é independente de valores passados ou 


\section{Camila Veneo Campos Fonseca \& Rodrigo Lanna Franco da Silveira}

futuros das variáveis explicativas, como também que os erros correntes são não correlacionados com os valores passados, presentes ou futuros de tais variáveis ${ }^{7}$.

Não obstante, os métodos tradicionais para estimação dos parâmetros de modelos com dados em painel não são os mais apropriados nos casos em que são especificados os chamados modelos autorregressivos ou dinâmicos, que incluem entre os regressores, além de valores defasados das variáveis explicativas, defasagens da variável dependente ${ }^{8}$. Isto porque, a premissa da exogeneidade estrita não é atendida, por definição, pelos valores defasados da variável dependente. A opção de incluir a variável dependente defasada entre as variáveis explicativas, por sua vez, é justificada pela premissa de haver uma tendência de reversão à média e um elevado grau de persistência do indicador do custo do capital de terceiros.

O GMM-Sis combina um sistema de regressões em diferenças com regressões em nível, para as quais os instrumentos são as defasagens das variáveis explicativas endógenas e pré-determinadas em diferença. Este método é capaz de mitigar problemas de endogeneidade na ausência de instrumentos estritamente exógenos ${ }^{9}$. O estimador GMM-Sis é obtido em dois estágios. No primeiro, assume-se que os erros são independentes e homocedásticos entre as unidades de corte transversal e ao longo do tempo. No segundo, os resíduos obtidos no primeiro estágio são utilizados para o cálculo de uma estimativa consistente da matriz de variância-covariância, sendo relaxada, portanto, a hipótese de independência e homocedasticidade.

Uma restrição quanto à implementação de ambos os estimadores surge quando a amostra conta com um número reduzido de unidades individuais. Nestes casos, se, por um lado, o estimador em um estágio é assintoticamente ineficiente, por outro, os erros padrão do estimador em dois estágios tendem a ser enviesados. Ou seja, enquanto a inferência assintótica a partir dos erros padrão obtidos pelo ajuste de um modelo GMM-one-step é relativamente mais realista, o estimador two-step é assintoticamente mais eficiente (ROODMAN, 2006). Uma forma de lidar com a tendência de a variante two-step subestimar

\footnotetext{
7 Entre as principais causas de quebra do pressuposto da exogeneidade estrita em modelos de finanças estão: i) retroalimentação da variável dependente para os regressores, ii) simultaneidade (isto é, ambiguidade no sentido das relações de causalidade esperadas), iii) erros de mensuração dos regressores (BARROS et al., 2010).

${ }^{8} \mathrm{O}$ pressuposto da exogeneidade estrita não é atendido, por definição, pelos valores defasados da variável dependente - isto requereria que os erros do modelo fossem não correlacionados com valores futuros dos regressores, no caso da variável dependente defasada isto implicaria, por exemplo, $\mathbb{E}\left(K d_{i t} a_{i}\right)=0$, o que não é válido. Além disso, se a heterogeneidade não observada for relevante, regressões estimadas por MQO, por exemplo, resultarão em estimadores enviesados $\mathrm{e}$ inconsistentes, uma vez que necessariamente $\mathbb{E}\left(K d_{i t-1} a_{i}\right) \neq 0$.

${ }^{9}$ Segundo Roodman (2006), este método é o ideal para a produção de inferências sobre as relações entre as variáveis de interesse nos casos de dados em painel como o deste trabalho em que há com 'poucos' anos e 'muitas' empresas, uma relação funcional linear, uma variável dependente dinâmica representativa do custo do capital de terceiros, variáveis independentes não estritamente exógenas, efeitos individuais fixos, autocorrelação e heterocedasticidade nas unidades individuais, mas não entre elas.
}

REAd | Porto Alegre - Edição 83 - N 1 - Janeiro/Abril 2016 - p. 106-133 
GOVERNANÇA CORPORATIVA E CUSTO DE CAPITAL DE TERCEIROS:

EVIDÊNCIAS ENTRE EMPRESAS BRASILEIRAS DE CAPITAL ABERTO

os erros padrão é recorrer à correção de Windmeijer para amostras finitas, realizada no presente estudo (BIONDI; TONETO JUNIOR, 2008).

\subsection{Amostra do estudo}

A pesquisa partiu de uma amostra composta por 349 empresas brasileiras não financeiras de capital aberto e ativas como sociedade anônima, segundo critérios do sistema Economática, entre 2010 e 2014. Foram desconsideradas as companhias: i) dos setores de finanças e seguros e de fundos; ii) com patrimônio líquido negativo durante o referido período; iii) com custo do capital de terceiros superior a 100\%. A amostra final compreende, portanto, um total de 230 empresas brasileiras não financeiras de capital aberto com ações negociadas na BM\&FBOVESPA entre 2010 e 2014.

O início em 2010 se justifica por corresponder a um período pós-crise do subprime e pós-estabelecimento e consolidação das novas regras contábeis em torno da adoção do IFRS (International Financial Reporting Standards), sob a Lei ${ }^{\circ}$ 11.638/2007. Foram coletados indicadores financeiros e de mercado, além de dados anuais do Balanço Patrimonial e da Demonstração de Resultados. A preferência foi pela extração de dados consolidados que, quando não disponíveis, foram substituídos por dados não consolidados. Cabe observar que alguns indicadores não puderam ser calculados para certas empresas em determinados anos. Estas variáveis foram consideradas missings nas análises estatísticas, caracterizando um painel não balanceado.

As informações sobre a adesão aos segmentos de listagem da BM\&FBOVESPA foram obtidas no Portal do Acionista e confirmadas no endereço eletrônico da BM\&FBOVESPA. Como explicitado na Tabela 1, 58\% das empresas da amostra encontravam-se listadas em algum dos segmentos diferenciados de governança corporativa em 2014, sendo 76,12\% delas pertencentes ao Novo Mercado (44,35\% do total de empresas da amostra).

Tabela 1 - Distribuição das empresas segundo níveis de governança corporativa em 2014

\begin{tabular}{ccc}
\hline Características & Número de empresas & $\begin{array}{c}\text { Participação no total geral da amostra* } \\
(\%)\end{array}$ \\
\hline \hline Segmentos diferenciados & 134 & 58,26 \\
- Nível 1 & 21 & 9,13 \\
- Nível 2 & 11 & 4,78 \\
- Novo Mercado & 102 & 44,35 \\
\hline
\end{tabular}

Fonte: Economática e Portal do Acionista. Elaboração própria. 


\section{Camila Veneo Campos Fonseca \& Rodrigo Lanna Franco da Silveira}

\section{ANÁLISE DOS RESULTADOS}

A Tabela 2 apresenta as estatísticas descritivas de cada uma das variáveis do estudo segmentadas por nível de governança corporativa. Empresas listadas nos segmentos de maior nível de governança possuíram, em média, menores custos de capital de terceiros $(K d)$ em relação às companhias do nível tradicional, sendo a diferença estatisticamente significativa. Estas companhias ainda se mostraram maiores (TAM), menos voláteis (VOLAT) e menos endividadas (DIV) que as empresas tradicionais (com significância estatística de 5\%).

Em relação às variáveis relativas à estrutura de propriedade, empresas pertencentes ao N1, N2 e NM tiveram uma menor participação do maior acionista sobre o total de ações emitidas $(P A R T)$, indicando menor concentração da propriedade frente às empresas do segmento tradicional. Adicionalmente, o número de ações PN frente ao total de ações emitidas (variável $P N$ ) foi inferior no N2. Por fim, a diferença entre o direito de propriedade e o de controle $(D I F)$ foi novamente menor nas empresas dos segmentos N2 e NM em relação às companhias do N1 e do mercado tradicional (com significância estatística de 1\%).

Apesar da criação dos segmentos diferenciados de governança ter incentivado a dispersão do poder para tomada de decisão, a estrutura de controle se mostrou concentrada no país. O maior acionista detém, em média, 49\% das ações com direito a voto. Em contrapartida, a participação do maior acionista no capital total das companhias da amostra é, em média, 41\%. Assim, o diferencial entre a participação no controle e na propriedade é de 8\%. Segundo Leal et al. (2002), em 1998, o maior acionista possuía, em média, 61\% do capital votante. Já Silveira et al. (2008a) observaram que, entre 1998 e 2002, tal indicador foi de 73,92\%. Mais recentemente Caixe e Krauter (2013), verificaram uma tendência à dispersão do controle tendo evidenciado uma queda na concentração do direito a voto, com o maior acionista detendo, em média, 50\% das ações ordinárias em 2009, apesar da participação na propriedade não ultrapassar $40 \%$. Ou seja, os resultados mostram que, apesar de haver uma tendência à redução nos últimos anos, o controle segue sendo altamente concentrado nas empresas brasileiras.

Tabela 2 - Estatísticas descritivas das variáveis do modelo, por nível de governança

\begin{tabular}{lcccccccc}
\hline & Kd & TAM & LUCR & VOLAT & DIV & PART & PN & DIF \\
\hline \hline Média & 0,200 & 13,79 & 0,660 & 0,04 & 2,820 & 0,410 & 0,210 & 0,080 \\
Trad. & 0,222 & 13,053 & 1,282 & 0,040 & 4,002 & 0,502 & 0,339 & 0,107 \\
N1 & 0,190 & 15,351 & 0,189 & 0,048 & 1,672 & 0,342 & 0,506 & 0,273 \\
N2NM & 0,185 & 14,178 & 0,226 & 0,033 & 1,905 & 0,344 & 0,043 & 0,020
\end{tabular}

REAd | Porto Alegre - Edição 83 - N 1 - Janeiro/Abril 2016 - p. 106-133 


\section{GOVERNANÇA CORPORATIVA E CUSTO DE CAPITAL DE TERCEIROS: EVIDÊNCIAS ENTRE EMPRESAS BRASILEIRAS DE CAPITAL ABERTO}

\begin{tabular}{|c|c|c|c|c|c|c|c|c|c|c|c|}
\hline \multicolumn{12}{|l|}{ Comparação } \\
\hline Trad. x N1 & $0,036^{* *}$ & 0,000 & $* * *$ & 0,583 & 0,161 & & 0,287 & & $0,000^{* * *}$ & $0,000^{* * *}$ & $0,000^{* * *}$ \\
\hline Trad. x N2NM & $0,000^{* * *}$ & 0,000 & $* * *$ & 0,245 & 0,008 & $* * *$ & 0,033 & ** & $0,000^{* * *}$ & $0,000^{* * *}$ & $0,000^{* * *}$ \\
\hline N1 x N2NM & 0,733 & 0,000 & $* * *$ & 0,565 & 0,001 & $* * *$ & 0,326 & & 0,904 & $0,000^{* * *}$ & $0,000^{* * *}$ \\
\hline Mediana & 0,160 & 13,960 & & 0,180 & 0,020 & & 1,330 & & 0,360 & 0,000 & 0,000 \\
\hline Trad. & 0,182 & 13,111 & & 0,175 & 0,026 & & 1,370 & & 0,468 & 0,424 & 0,028 \\
\hline N1 & 0,171 & 15,836 & & 0,168 & 0,025 & & 1,039 & & 0,331 & 0,617 & 0,268 \\
\hline $\mathrm{N} 2 \mathrm{NM}$ & 0,147 & 14,212 & & 0,179 & 0,024 & & 1,372 & & 0,310 & 0,000 & 0,000 \\
\hline \multicolumn{12}{|l|}{ Comparação } \\
\hline Trad. x N1 & $0,064^{*}$ & 0,000 & $* * *$ & 0,976 & 0,622 & & 0,009 & *** & $0,000^{* * *}$ & $0,000^{* * *}$ & $0,000^{* * *}$ \\
\hline Trad. x N2NM & $0,000^{* * *}$ & 0,000 & $* * *$ & 0,347 & 0,155 & & 0,436 & & $0,000^{* * *}$ & $0,000^{* * *}$ & $0,000^{* * *}$ \\
\hline N1 x N2NM & $0,068^{*}$ & 0,000 & $* * *$ & 0,444 & 0,186 & & 0,000 & . & 0,607 & $0,000^{* * *}$ & $0,000^{* * *}$ \\
\hline Desvio-padrão & 0,140 & 1,740 & & 13,190 & 0,040 & & 15,000 & & 0,230 & 0,270 & 0,150 \\
\hline Trad. & 0,148 & 1,898 & & 20,489 & 0,046 & & 22,254 & & 0,255 & 0,265 & 0,158 \\
\hline N1 & 0,103 & 1,626 & & 0,192 & 0,060 & & 3,292 & & 0,150 & 0,210 & 0,185 \\
\hline $\mathrm{N} 2 \mathrm{NM}$ & 0,142 & 1,164 & & 0,652 & 0,032 & & 1,927 & & 0,185 & 0,149 & 0,078 \\
\hline \multicolumn{12}{|l|}{ Comparação } \\
\hline Trad. x N1 & $0,000^{* * *}$ & 0,031 & $* *$ & $0,000^{* * * *}$ & 0,002 & & 0,000 & $* * *$ & $0,000^{* * *}$ & $0,001^{* * *}$ & $0,050^{* *}$ \\
\hline Trad. x N2NM & 0,417 & 0,000 & $* * *$ & $0,000^{* * *}$ & 0,000 & **** & & $* * *$ & $0,000^{* * *}$ & $0,000^{* * *}$ & $0,000^{* * *}$ \\
\hline $\mathrm{N} 1 \mathrm{x}$ N2NM & $0,000^{* * *}$ & 0,000 & $* * *$ & $0,000^{* * * *}$ & 0,000 & $* * *$ & 0,000 & **** & $0,003^{* * *}$ & $0,000^{* * *}$ & $0,000^{* * *}$ \\
\hline
\end{tabular}

Nota: A comparação utiliza o p-valor para o teste de hipótese em que, sob H0, a diferença entre as estatísticas é igual a zero. Os símbolos ${ }^{* * *},{ }^{*} \mathrm{e}$ * denotam a significância estatística das estimativas nos níveis $1 \%, 5 \%$ e 10\%, respectivamente.

Fonte: Resultados da pesquisa.

Para verificar a relevância da adoção de melhores práticas de governança corporativa, assim como dos demais atributos financeiros considerados, na determinação do custo do capital de terceiros, foi realizada, além da análise descritiva, uma modelagem econométrica com dados em painel. A especificação do modelo mensurado pelo GMM-Sis foi embasada pelos argumentos encontrados na literatura acerca dos potenciais determinantes do custo do capital de terceiros e pela análise teórica discutida ao longo da seção $3.2^{10}$. Particularmente, os fatores VOLAT, DIV e DIF foram definidos como endógenos, os atributos LUCR, PART e PN como pré-determinados, enquanto as variáveis explicativas TAM e $N 2 N M$ foram definidas como exógenas, ou seja, independentes dos erros correntes e passados.

\footnotetext{
${ }^{10}$ Vale observar que os parâmetros do modelo foram também estimados pelos métodos Mínimos Quadrados Ordinários (MQO), Efeitos Fixos (EF-Within) e Efeitos Aleatórios (EA-MQG). No entanto, a partir do teste da "exogeneidade estrita" dos regressores proposto por Wooldridge (2002), observou-se que um ou mais regressores não se apresentaram como estritamente exógenos. Portanto, o pressuposto da exogeneidade estrita não teve validade, sendo o GMM-Sis a proposta de estimação mais eficiente para solucionar, ou ao menos minimizar, potenciais problemas de endogeneidade.
} 


\section{Camila Veneo Campos Fonseca \& Rodrigo Lanna Franco da Silveira}

Justifica-se a caracterização das variáveis VOLAT, DIV e DIF como endógenas, ou seja, potencialmente correlacionadas com valores passados e presentes dos erros, pela provável influência recíproca da variável dependente sobre as mesmas. Por exemplo, apesar de um elevado custo de capital não necessariamente implicar um menor nível de endividamento ou maior volatilidade diante de boas perspectivas futuras de rentabilidade e crescimento, pode-se argumentar uma possível influência recíproca do custo do capital de terceiros sobre as variáveis DIV e VOLAT. A justificada pode ser uma mudança repentina no cenário macroeconômico, a qual poderia impactar com mais intensidade empresas consideradas arriscadas pelos provedores de recursos, especialmente no curto prazo.

Já as variáveis LUCR, PART e $P N$ foram tratadas como potencialmente correlacionadas com os erros passados, dada a possibilidade de haver retroalimentação da variável de resposta para os regressores. De forma prática, por exemplo, a busca pela maximização da riqueza pessoal de uma gestão oportunista, incorporada preliminarmente como um choque no modelo, pode impactar o custo do capital de terceiros no período presente e, apesar de não exercer influência sobre as variáveis explicativas contemporaneamente, pode interferir na lucratividade futura do negócio, assim como na maior emissão de ações preferenciais frente ao prêmio de liquidez associado às mesmas.

Para a variável dependente e as variáveis endógenas, foram consideradas como variáveis instrumentais válidas aquelas defasadas de dois ou mais períodos. No modelo especificado neste trabalho, foram consideradas dois e três períodos de defasagem. Para as variáveis pré-determinadas, a defasagem de um ou mais períodos já foi suficiente para validar os instrumentos, de modo que foram consideradas defasagens de um e dois períodos. Como as variáveis estritamente exógenas não são correlacionadas com a heterogeneidade não observada, sua diferença serve como instrumento na estimação do modelo ${ }^{11}$. Os resultados da estimação do modelo dinâmico pelo GMM-Sis, em um e dois estágios (one-step e two-step), são apresentados na Tabela 3.

Tabela 3 - Resultados das regressões estimadas por GMM-Sis

\begin{tabular}{lcccc}
\hline Regressores & \multicolumn{2}{c}{$\begin{array}{c}\text { GMM-Sis } \\
(\text { one-Step })\end{array}$} & \multicolumn{2}{c}{$\begin{array}{c}\text { GMM-Sis } \\
\text { (two-step })\end{array}$} \\
\hline \hline$K d_{t-1}$ & $0,3594^{* * *}$ & $(0,119)$ & $0,2613^{* *}$ & $(0,117)$ \\
$T A M$ & $-0,0042^{2}$ & $(0,007)$ & $-0,0031$ & $(0,006)$
\end{tabular}

\footnotetext{
${ }^{11}$ A presença de múltiplos instrumentos para as variáveis explicativas permite a consideração de condições de momento adicionais, o que torna o modelo sobreidentificado. A sobreidentificação, quando possível, normalmente aumenta a eficiência da estimação e permite testar a validade dos instrumentos utilizados. No entanto, a inclusão de um número excessivo de instrumentos, relativamente ao número de observações, pode tornar os resultados viesados. Se o problema da endogeneidade não for solucionado, o viés aproximará os resultados daqueles obtidos pela estimação via MQO. Tal constatação justifica a escolha metodológica de limitar o número de defasagens utilizadas como instrumentos (ROODMAN, 2006).
}

REAd | Porto Alegre - Edição 83 - N 1 - Janeiro/Abril 2016 - p. 106-133 
GOVERNANÇA CORPORATIVA E CUSTO DE CAPITAL DE TERCEIROS:

EVIDÊNCIAS ENTRE EMPRESAS BRASILEIRAS DE CAPITAL ABERTO

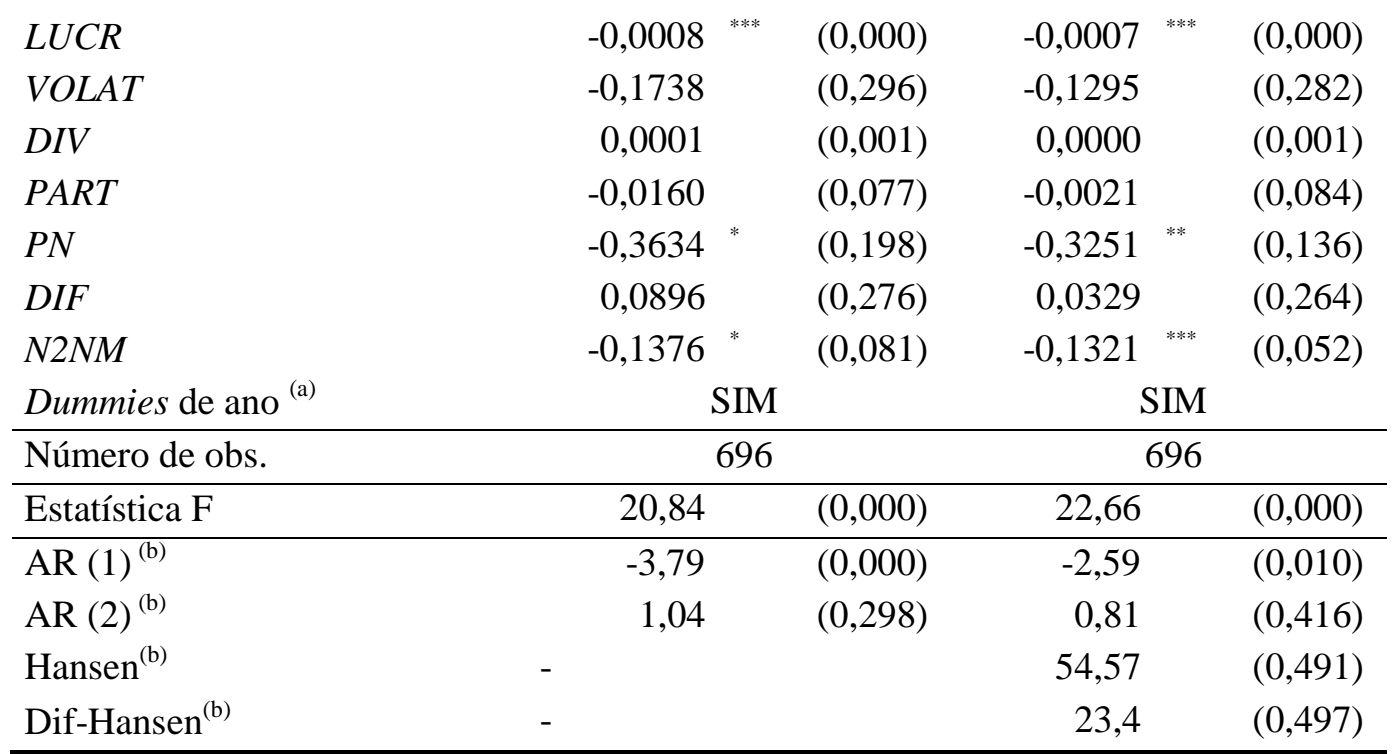

Notas: os erros-padrão robustos estão entre parênteses e os símbolos ${ }^{* * * * *}$, e " denotam a significância estatística das estimativas nos níveis $1 \%, 5 \%$ e $10 \%$, respectivamente.

(a) A sinalização 'SIM' indica que as variáveis dummy de ano foram incorporadas no modelo, mas seus coeficientes não foram apresentados devido a uma limitação de espaço.

(b) Para todos os testes, reporta-se a estatística do teste e, entre parênteses o seu nível descritivo (p-valor).

Fonte: Resultados da pesquisa.

O resultado do teste de sobreidentificação de Hansen para o GMM-Sis em dois estágios levou à não-rejeição da hipótese nula de que todas as variáveis instrumentais são não correlacionadas com o termo de erro do modelo. $\mathrm{O}$ resultado sugere, portanto, que os instrumentos utilizados foram válidos, ou seja, as condições de momento estabelecidas foram razoáveis. Uma vez que a hipótese nula do teste de Hansen/Sargan não foi rejeitada para o modelo estimado pelo Método dos Momentos Generalizado em Diferenças (GMM-Dif), o teste de Dif-Hansen constitui-se num teste da validade dos instrumentos adicionados pelo método GMM-Sis. Seus resultados indicaram a não-rejeição da hipótese nula, oferecendo suporte às condições do modelo. Por fim, os testes de autocorrelação dos erros propostos por Arellano e Bond (1991) resultaram em uma estatística negativa e significativa de primeira ordem e positiva e não significativa de segunda ordem, ou seja, esta ferramenta de diagnóstico constata a presença de autocorrelação negativa de primeira ordem entre os erros transformados por primeira diferença e os regressores, mas não de segunda, corroborando a hipótese de que $\mu_{i t}$ é não autocorrelacionado.

A partir da estimação pelo método GMM-Sis em dois estágios, as hipóteses de haver uma tendência de reversão à média e um elevado grau de persistência do indicador do custo do capital de terceiros foram confirmadas. O custo do capital de terceiros no período $t-1, K d_{t}$ 1, é estatisticamente significativo e tem relação positiva em relação ao custo da dívida 


\section{Camila Veneo Campos Fonseca \& Rodrigo Lanna Franco da Silveira}

contemporâneo. O coeficiente, $35,94 \%$, demonstra a magnitude da relação dinâmica entre o custo da dívida atual e passado.

Os resultados apresentados na Tabela 3 indicam ainda a existência de relação estatisticamente significativa entre a lucratividade $(L U C R)$ da empresa e o seu custo do capital, confirmando a proposição de que empresas com maior lucratividade tendem a defrontar-se com menores custos de endividamento. A razão para tanto seria a menor probabilidade de a companhia emitir títulos arriscados e/ou suspender investimentos promissores que, ao reduzir os riscos de inadimplência e falência, melhoraria as expectativas dos credores, resultando na queda do custo do capital de terceiros. Por outro lado, as variáveis $T A M, V O L A T$ e $D I V$ não apresentaram significância estatística, impedindo a confirmação das mesmas como fatores determinantes do custo do capital de terceiros.

Em relação às variáveis de interesse, constatou-se uma relação negativa e estatisticamente significativa entre a emissão de ações PN e o custo da dívida. Como discutido no tópico 1.2, grande parte da literatura obteve indícios de que a utilização deste artifício, ao corroborar o distanciamento entre o direito de controle e a participação no fluxo de caixa e, consequentemente, ampliar o risco de expropriação de minoritários e credores por controladores, têm um efeito negativo sobre o valor de mercado das empresas (CLAESSENS et al., 2002; CAIXE \& KRAUTER, 2013; LAUTERBACH \& PAJUSTE, 2015). Os resultados obtidos nesta pesquisa, no entanto, evidenciam que empresas emissoras de uma maior proporção de ações sem direito a voto apresentam um menor custo de capital de terceiros. Este efeito pode estar atrelado ao prêmio de liquidez atribuído às ações PN, o que, na visão de Claessens et al. (2000), resulta num descolamento entre o valor intrínseco das mesmas - reduzido devido ao risco de expropriação - e o valor pelo qual elas são transacionadas. No limite, a transação de ações sem direito a voto, na visão dos agentes atuantes no mercado brasileiro, poderia incrementar o valor da organização, reduzindo os riscos financeiros e, por conseguinte, o custo da dívida.

Quanto à proxy para o 'padrão de governança corporativa' (N2NM), esta foi estatisticamente significativa, ou seja, a adesão ao N2 e ao NM foi relevante para explicar o custo do capital de terceiros. Desta forma, os resultados, alinhados aos da literatura, sugerem que a tentativa de minimizar as distorções causadas pela existência de informação assimétrica, assim como a sinalizar o comprometimento com melhores práticas de governança, ao mesmo tempo em que mitiga os problemas da seleção adversa e do risco moral, reduz os custos associados ao conflito de agência. A consequente maior capacidade de monitoramento e mensuração dos riscos por outsiders resulta em um menor custo de capital (HEALY;

REAd | Porto Alegre - Edição 83 - N 1 - Janeiro/Abril 2016 - p. 106-133 


\section{GOVERNANÇA CORPORATIVA E CUSTO DE CAPITAL DE TERCEIROS:} EVIDÊNCIAS ENTRE EMPRESAS BRASILEIRAS DE CAPITAL ABERTO

PALEPU, 2001, BUSHMAN; SMITH, 2001; EASLEY; O’HARA, 2004; LANZANA et al., 2006). Além disso, a adesão voluntária às práticas voltadas à proteção aos direitos dos acionistas minoritários e credores sinalizaria ao mercado um compromisso do controlador com a maximização do valor da companhia em detrimento da extração de benefícios privados de controle, alterando as expectativas em prol da redução do custo do capital. Por outro lado, os coeficientes das variáveis $P A R T$ e $D I F$ não apresentaram significância estatística.

O Quadro 2 apresenta um resumo dos principais resultados da estimação, apontando para as variáveis que tiveram relação estatisticamente significativa em relação ao custo de capital das empresas brasileiras de capital aberto no período 2010-2014.

Quadro 3 - Resumo dos resultados estatisticamente significativos obtidos na estimação do modelo do estudo.

\begin{tabular}{|l|c|l|}
\hline \multicolumn{1}{|c|}{ Variável } & Relação com o $K d$ & \multicolumn{1}{c|}{ Interpretação } \\
\hline \hline $\begin{array}{l}\text { Custo da dívida em } t-1 \\
\left(K d_{t-1}\right)\end{array}$ & Positiva & $\begin{array}{l}\text { O custo da dívida contemporâneo tem relação } \\
\text { positiva em relação ao custo do período anterior } \\
\text { devido a uma tendência de reversão à média. }\end{array}$ \\
\hline Lucratividade $(L U C R)$ & Negativa & $\begin{array}{l}\text { Empresas com maior margem operacional, por } \\
\text { apresentarem menores riscos de insolvência e } \\
\text { falência, defrontam-se com um menor custo do } \\
\text { capital de terceiros. }\end{array}$ \\
\hline $\begin{array}{l}\text { Emissão de ações } \\
\text { preferenciais }(P N)\end{array}$ & $\begin{array}{l}\text { A emissão de ações preferenciais, devido ao prêmio } \\
\text { de liquidez atribuído às mesmas, reduz o custo da } \\
\text { dívida. }\end{array}$ \\
\hline $\begin{array}{l}\text { Adesão ao Nível 2 e } \\
\text { Novo Mercado }(N 2 N M)\end{array}$ & Negativa & $\begin{array}{l}\text { A adesão ao Nível 2 e Novo Mercado, por exigir o } \\
\text { comprometimento com práticas mais rigorosas de } \\
\text { governança corporativa, reduz o custo do capital de } \\
\text { terceiros. }\end{array}$ \\
\hline
\end{tabular}

Fonte: Resultados da pesquisa.

Vale ainda observar que o modelo foi ainda estimado com duas especificações alternativas: i) a variável $N 2 N M$ foi substituída por uma variável dummy $(G C)$ em que empresas listadas nos Níveis 1, 2 e Novo Mercado assumiram valor um e as companhias do segmento tradicional tiveram valor zero; ii) as variáveis explicativas TAM, RENT, VOLAT, e $D I V$ foram incluídas defasadas de um período. Em ambos os casos, os resultados foram consistentes com os apresentados anteriormente, apontando no sentido proposto pela hipótese do trabalho de que o comprometimento da empresa com um melhor padrão de governança exerce um impacto negativo sobre o custo do capital de terceiros. Adicionalmente, o modelo no qual a variável $N 2 N M$ foi substituída pela variável $G C$ forneceu indícios de que a listagem no Nível 1, por presumir um nível de evidenciação das informações superior ao requerido por lei, também exerce uma influência negativa sobre o custo da dívida. 


\section{Camila Veneo Campos Fonseca \& Rodrigo Lanna Franco da Silveira}

\section{CONSIDERAÇÕES FINAIS}

O presente trabalho avaliou a relação entre a adoção de melhores práticas de governança e o custo do capital de terceiros nas empresas brasileiras não financeiras de capital aberto no período 2010-2014. De forma a atingir tal objetivo, utilizou-se um modelo de dados de painel com 230 companhias brasileiras não financeiras, com ações negociadas na BM\&FBOVESPA, sendo a estimação realizada pelo GMM-Sis. Os resultados mostraram que um melhor padrão de governança corporativa resultou na redução do custo da dívida. Adicionalmente, foram encontrados indícios de que a emissão de ações PN exerceu influência positiva sobre o custo da dívida, resultado possivelmente associado ao prêmio de liquidez concedido às ações sem direito a voto.

Em geral, o modelo empírico corrobora os preceitos teóricos discutidos no decorrer da pesquisa. A melhora na qualidade das demonstrações financeiras e contábeis subjacente à maior transparência e credibilidade requeridas nas informações fornecidas ao mercado, assim como o comprometimento com a proteção aos direitos dos acionistas minoritários e credores, reduzem o conflito de agência e a assimetria informacional inerente às transações efetuadas no mercado financeiro e, consequentemente, exercem um impacto positivo sobre a percepção dos credores (EASLEY \& O’HARA, 2004; BUSHMAN \& SMITH, 2001). Alinhado com a perspectiva de Shleifer e Vishny (1997), uma expectativa positiva quanto ao recebimento dos retornos esperados sobre suas inversões, associada à mudança na forma como as empresas são geridas, assim como sobre os resultados provenientes desta otimização, repercutem na redução do custo de capital de terceiros.

Os resultados evidenciam a existência de um efeito associado à adesão aos níveis diferenciados de governança sobre o custo da dívida no sentido de diminuí-lo, confirmando estudos prévios no mercado brasileiro que constataram relação inversa entre disclosure voluntário e custo da dívida (Lima, 2009; Castro e Martinez, 2009 e Angonese et al., 2013). Ao aderir às normas mais restritivas, com maior transparência e enforcement que as consignadas na lei, o estudo aponta na direção de que as empresas influenciaram a percepção dos provedores de recursos reduzindo o seu custo do capital de terceiros. Em geral, as empresas que iniciaram a negociação de ações em bolsa nos últimos anos têm utilizado essencialmente o Novo Mercado. Tal fato pode indicar o reconhecimento por parte dos acionistas dos efeitos benéficos da adoção das regras previstas para listagem, ou seja, da importância de uma maior transparência e proteção aos direitos dos acionistas minoritários, para a captação de recursos a menores custos.

REAd | Porto Alegre - Edição 83 - N 1 - Janeiro/Abril 2016 - p. 106-133 


\section{GOVERNANÇA CORPORATIVA E CUSTO DE CAPITAL DE TERCEIROS:} EVIDÊNCIAS ENTRE EMPRESAS BRASILEIRAS DE CAPITAL ABERTO

Particularmente, a criação do Novo Mercado e a elevada adesão das companhias abertas brasileiras, principalmente a partir de 2006, levou a uma redução expressiva da diferença entre os direitos de controle e propriedade, tendo em vista a exigência quanto à emissão de somente ações ordinárias. Se tal constatação, por um lado, corrobora o efeito positivo que a adoção de melhores práticas de governança tem sobre a dispersão do controle e, consequentemente, o custo do capital, por outro, evidencia uma limitação dos estudos voltados à análise das empresas de capital aberto, indicando a relevância de estender a pesquisa às empresas de capital fechado cuja propriedade é caracteristicamente concentrada.

Futuras pesquisas podem também abarcar informações referentes às estruturas resultantes de pirâmides societárias. Neste estudo considerou-se somente a estrutura de propriedade e controle direta. Tal limitação, no entanto, não é proibitiva uma vez que este mecanismo para manutenção do poder de controle não somente é incomum no Brasil, como, e consequentemente, não resulta em diferenças expressivas entre o grau de concentração observado nas estruturas direta e indireta (LEAL et al., 2002; SILVA; LEAL, 2003). Por fim, outros indicadores do custo do capital de terceiros podem ser calculados tendo em vista refinar a análise empírica, dadas as limitações existentes no indicador utilizado nesta pesquisa. Uma alternativa de cálculo, empregada em diversos estudos internacionais, é o yield spread entre as taxas incidentes sobre os papéis emitidos pela empresa e as de ativos livres de risco com duração equivalente. Todavia, a principal dificuldade neste sentido é o acesso às informações necessárias para um número suficiente de empresas, principalmente no caso brasileiro.

A disseminação de uma postura pró-governança entre as empresas brasileiras eleva o grau de confiança dos investidores pulverizados, retroalimentando o processo de desenvolvimento do mercado de capitais brasileiro. Ou seja, uma vez que o aprimoramento das práticas de governança leve a taxas de desconto menores e, portanto, títulos corporativos mais bem avaliados, tem-se, a partir da redução do custo do capital, a ampliação do papel exercido pelo mercado de capitais na captação de recursos para o investimento. Por outro lado, o desenvolvimento do mercado de capitais é acompanhado por uma maior transparência e enforcement das regras subjacentes à participação dos investidores, acarretando o aprimoramento das práticas de governança (SILVEIRA, 2010). A dupla causalidade entre o desenvolvimento do mercado de capitais e os aspectos da governança corporativa resulta, portanto, em um ciclo virtuoso de aprofundamento financeiro, tornando o estudo de seus efeitos de grande relevância para a formulação de políticas que ampliem a transparência, 


\section{Camila Veneo Campos Fonseca \& Rodrigo Lanna Franco da Silveira}

reduzam o potencial de expropriação de minoritários e credores e, associadamente, incentivem o desenvolvimento do mercado de capitais nacional.

\section{REFERÊNCIAS}

ANGONESE, R.; FANK, O. L.; OLIVEIRA, C. R.; BEZERRA, F. A. Divulgação de informações voluntárias na internet como determinante do custo do capital de terceiros. Periódicos UEM - Paraná, v. 32, n. 3, p. 57-71, 2013.

ARELLANO, M.; BOND, S. Some tests of specification for panel data: Monte carlo evidence and an application to employment equations. Review of Economic Studies, v. 58, p. 277-297, 1991.

BARROS, L. A. B. C.; CASTRO JUNIOR, F. H. F.; SILVEIRA, A. D. M., \& BERGMANN, D. R. Endogeneity in Corporate Finance Empirical Research. (April 20, 2010). Disponível em <http://papers.ssrn.com/abstract=1593187>. Acesso em maio 2015.

BARROS, L. A.; SILVEIRA, A. Excesso de confiança, otimismo gerencial e os determinantes da estrutura de capital. Revista Brasileira de Finanças, v. 6, n. 3, p. 293-334, 2008.

BASTOS, D. D.; KAKAMURA, W. T. Determinantes da estrutura de capital das companhias abertas no Brasil, México e Chile no período 2001-2006. Revista de Contabilidade \& Finanças, v. 20, n. 50, p. 75-94, 2009.

BEBCHUK, L. A rent-protection theory of corporate ownership and control. Economics and Business Discussion Paper Series n. 260, Harvard Law School John M. Olin Center for Law, 1999.

BERLE, A.; MEANS, G. The modern corporation and private property. New York: MacMillan, 1932.

BIONDI, R. L.; TONETO JUNIOR., R. Regime de Metas Inflacionárias: os Impactos sobre o Desempenho Econômico dos PAíses. Revista de Teoria e Pesquisa Econômica, v. 38, n. 4, p. 873-903, 2008.

BLACK, B. S.; CARVALHO, A. G.; GORGA, E. An overview of Brazilian corporate governance. Cornell Law Faculty Publications Paper 101, Cornel University Law School, 2008.

BLUNDELL, R.; BOND, S. Initial conditions and moment restrictions in dynamic panel data models. Journal of Econometrics, v. 87, p. 115-143, 1998.

BUSHMAN, R. M.; SMITH, A. J. Financial accounting information and corporate governance. Journal of Accounting \& Economics, v. 32, 2001.

CAIXE, D. F.; KRAUTER, E. A influência da estrutura de propriedade e controle sobre o valor de mercado corporativo no Brasil. Revista Contabilidade \& Finanças USP, v. 24, n. 62, p. 142-153, 2013. 


\section{GOVERNANÇA CORPORATIVA E CUSTO DE CAPITAL DE TERCEIROS:} EVIDÊNCIAS ENTRE EMPRESAS BRASILEIRAS DE CAPITAL ABERTO

CAMPOS, T. L. C. Estrutura da propriedade e desempenho econômico: uma avaliação empírica para as empresas de capital aberto no Brasil. Revista de Administração - RAUSP, v. 41, n. 4, p. 369-380, 2006.

CARVALHO, A. Governança corporativa no Brasil em perspectiva. Revista de Administração - RAUSP, v. 37, n. 3, p. 19-32, 2002.

CASTRO, M. A. R.; MARTINEZ, A. L. Income smoothing, custo de capital de terceiros e estrutura de capital no Brasil. Revista de Administração Mackenzie, v. 10, n. 6, p. 25-46, 2009

CHENG, M.; DHALIWAL, D.; ZHANG, Y. Does investment efficiency improve after the disclosure of material weaknesses in internal control over financial reporting? Journal of Accounting and Economics, v. 56, n. 1, p. 1-18, 2013.

CICOGNA, M. P. V.; TONETO JUNIOR., R.; VALLE, M. R. O impacto da adesão a padrões mais elevados de governança sobre o financiamento empresarial. Revista de Administração RAUSP, v. 42, n. 1, p. 52-63, 2007.

CLAESSENS, S.; DJANKOV, S.; FAN, J. P. H.; LANG, L. H. P. Disentangling the incentive and entrenchment effects of large shareholdings. Journal of Finance, v. 57, n. 6, p. 27412771, 2002.

CLAESSENS, S.; KLINGEBIEL, D.; LUBRANO, M. Corporate governance reform issues in the Brazilian equity markets. Working Paper - World Bank, 2000.

CUNHA, J. V. A.; RIBEIRO, M. S. Divulgação Voluntária de informações de natureza social: um estudo nas empresas brasileiras. Revista de Administração Eletrônica, v. 1, n. 1, 2008.

EASLEY, D.; O'HARA, M. Information and the cost of capital. Journal of Finance, v.59, n.4, p. 1553- 1583, 2004.

FERREIRA, R. N.; SANTOS, A. C.; LOPES, A. L. M.; FONSECA, R. A.; NAZARETH, L. G. C. Governança corporativa, eficiência, produtividade e desempenho. Revista de Administração Mackenzie, v.14, n.4, 2013.

HAIL, L. The impact of voluntary corporate disclosures on the ex-ante cost of capital for Swiss firms. The European Accounting Review, v. 11, n. 4, p. 741-773, 2002.

HARRIS, M.; RAVIV, A. Corporate control contest and capital structure. Journal of Financial Economics, v. 20, n. 1-2, p. 55-86, 1988.

HEALY, P.M.; PALEPU, K.G. Information asymmetry, corporate disclosure, and the capital markets: a review of the empirical disclosure literature. Journal of Accounting and Economics, v.31, n.1-3, p.405-440, 2001.

JENSEN, M. C.; MECKLING, W. H. Theory of the firm: managerial behavior, agency costs and ownership structure. Journal of Financial Economics, v. 3, n. 4, p. 305-360, 1976.

KAPPLER, L.; LOVE, I. Corporate governance, investor protection, and performance in emerging markets. Working Paper n. 2818, World Bank Policy Research, 2002. 


\section{Camila Veneo Campos Fonseca \& Rodrigo Lanna Franco da Silveira}

KHURANA, I. K.; RAMAN, K. K.; WANG, D. Weakened outside shareholder rights in dualclass firms and timely loss reporting. Journal of Contemporary Accounting \& Economics, v. 9, n. 2, p. 203-230, 2013.

LA PORTA, R. et al. Investor protection and corporate governance. Journal of Financial Economics, v. 58, n. 1-2, p. 3-27, 2000.

LANZANA, A. P.; SILVEIRA, A. M.; FAMÁ, R. Existe relação entre disclosure e governança corporativa no Brasil? In: ENANPAD, 30, 2006, Salvador-BA. Anais..., 2006.

LAUTERBACH, B.; PAJUSTE, A. The long-term valuation effects of voluntary dual class share unifications. Journal of Corporate Finance, v. 31, p. 171-185, 2015.

LEAL, R.; SILVA, A.; VALADARES, S. Estrutura de controle das companhias brasileiras de capital aberto. Revista de Administração Contemporânea, v. 6, n. 1, p. 7-18, 2002.

LIMA, G. Nível de evidenciação x custo da dívida das empresas brasileiras. Revista Contabilidade \& Finanças USP, v. 20, n. 49, p. 95-108, 2009.

MAYER, C. Corporate governance, competition and performance. Working Paper n. 164, School of Management Studies, University of Oxford, 1996.

MELO, R. S.; BATISTIA, P. C. S.; MACEDO, A. C. M.; COSTA, R. B. L. A contribuição da governança corporativa para o desempenho das empresas brasileiras de capital aberto. Revista de Gestão da USP, v. 20, n. 1, 2013.

MIGLANI, S.; AHMED, K.; HENRY, D. Voluntary corporate governance structure and financial distress: evidence from Australia. Journal of Contemporary Accounting \& Economics, v.11, n.1, p. 18-30, 2015.

MYERS, S. The capital structure puzzle. The Journal of Finance, v. 39, n. 3, 1984.

NAKAMURA, W. T.; GOMES, E. A.; ANTUNES, M. T. P.; MURÇAL, E. F. Estudo sobre os níveis de disclosure adotados pelas empresas brasileiras e seu impacto no custo de capital. In: ENANPAD, 30., 2006, Salvador-BA. Anais..., 2006.

PEROBELli, F. F. C.; FAMÁ, R. Fatores determinantes da estrutura de capital para empresas latino-americanas. Revista de Administração Contemporânea, v. 7, n. 1, p. 9-35, 2003.

RONEN, J.; YAARI, V. Incentives for voluntary disclosure. Journal of Financial Markets, v. 5, n. 3, p. 349-390, 2002.

ROODMAN, D. How to do Xtabond2: an introduction to difference and system GMM in Stata. Working Paper n. 103, Center for Global Development, 2006.

SENGUPTA, P. Corporate Disclosure Quality and the Cost of Debt. The Accounting Review, v. 73, n. 4, p. 459-474, 1998.

SHLEIFER, A.; VISHNY, R. W. A survey of corporate governance. Journal of Finance, v. 52, n. 2, p. 737-783, 1997.

REAd | Porto Alegre - Edição 83 - N 1 - Janeiro/Abril 2016 - p. 106-133 
GOVERNANÇA CORPORATIVA E CUSTO DE CAPITAL DE TERCEIROS:

EVIDÊNCIAS ENTRE EMPRESAS BRASILEIRAS DE CAPITAL ABERTO

SILVA, A.; LEAL, R. Corporate governance, market valuation and dividend policy in Brazil. Working Paper Series n. 390, Coppead, 2003.

SILVA, E. S.; SANTOS, J. F.; ALMEIDA, M. A. Os efeitos dos mecanismos de governança corporativa sobre os ratings de crédito das debêntures. Revista de Negócios, vol. 17, n.3, p. 80-93, 2012.

SILVEIRA, A. D. M.; LANZANA, A. P.; BARROS, L. A. B.; FAMÁ, F. Efeito dos acionistas controladores no valor das companhias abertas brasileiras. Revista de Administração - RAUSP, v. 39, n. 4, p. 362-372, 2004.

SILVEIRA, A. D. M. Governança Corporativa no Brasil e no Mundo - Teoria e Prática. Rio de Janeiro: Campus Editora, 2010.

SILVEIRA, A. D. M.; BARROS, L.; FAMÁ, R. Atributos corporativos e concentração acionária no Brasil. Revista de Administração de Empresas, v. 48, n. 2, p. 51-66, 2008 a.

SILVEIRA, A. D. M.; PEROBELLI, F.; BARROS, L. A. B. Governança corporativa e os determinantes da estrutura de capital: evidências empíricas no Brasil. Revista de Administração Contemporânea, v. 12, n. 3, p. 763-788, 2008 b.

SOARES, R.; KLOECKNER, G. O. Endividamento em firmas com alta propensão à expropriação: o caso de firmas com um controlador. Revista de Administração de Empresas, v. 48, n. 4, p. 79-93, 2008.

STIGLITZ, J. Government, financial markets, and economic development. Working Paper n. w3669, National Bureau of Economic Research, 1991.

STULZ, R. M. Managerial control of voting rights. Journal of Financial Economics, v. 20, p. 25-54, 1988.

VERRECCHIA, R.E. Essays on disclosure. Journal of Accounting and Economics, v. $32 \mathrm{n}$. 1-3, p. 97-180, 2001.

WATSON, A.; SHRIVES, P.; MARSTON, C. L. Voluntary disclosure of accounting ratios in the UK. British Accounting Review, v. 34, n. 4, p. 289-313, 2002.

ZHU, F. Corporate governance and the cost of capital: an international study. International Review of Finance, v. 13, n. 3, p. 393-429, 2014. 